\title{
Extensão universitária na ESALQ-USP: o caso dos agricultores de São Pedro-SP
}

\author{
MARLY TERESINHA PEREIRA
}

\begin{abstract}
"Vá ao povo, ame-o. Aprenda com ele, sirva-o. Comece com o que ele tem, aproveite o que ele sabe. Mas quando nós, dos melhores líderes a tarefa chega ao fim, quando seu trabalho termina, todo povo diz:

'- Fizemos tudo isso sozinhos'."
\end{abstract}

(poema chinês)

$\mathrm{E}$ MBORA reconhecendo a importante contribuição que as Faculdades de Ciências Agrárias têm dado à modernização da agricultura brasileira, não podemos deixar de mencionar a sua ausência no que diz respeito ao processo de desenvolvimento rural. Por permanecerem praticamente à margem da realidade rural, principalmente das populações mais marginalizadas, suas participações nas ações voltadas para a aplicação dos resultados de suas pesquisas sobre essa realidade e sobre o potencial produtivo dos recursos existentes não são expressivas. Tal situação resulta em deficiências na formação de seus profissionais, os quais, muitas vezes, não têm condições de contribuir na análise e na formulação de políticas, na execução de atividades destinadas aos agricultores familiares e suas comunidades, ou na melhoria do desempenho dos organismos de apoio ao agro.

O desenvolvimento rural - e com ele o conseqüente aumento na produção de alimentos, produtos de exportação, nível de emprego e renda - não será conseguido por um simples sistema de transferência de tecnologia, por maiores que sejam sua eficiência e eficácia. Serão necessários profissionais de ciências agrárias altamente capacitados para atuarem nas áreas de pesquisa, assistência técnica, ensino e extensão rural, que possuam sólida formação técnico-científica nos diversos campos das ciências agrárias, aliada a larga experiência vivencial do meio rural e de seus problemas.

Dentro dessa perspectiva, torna-se evidente a necessidade de integração concreta das três funções básicas da Universidade - ensino, pesquisa e extensão. Sem essa integração, dificilmente se poderá pensar que ela terá condições de preparar profissionais com a qualificação que o país exige. Não basta, entretanto, 
que ensino, pesquisa e extensão universitária se integrem "intramuros", torna-se necessário que seja estabelecido também um contato estreito com a comunidade, uma relação dinâmica com o sistema produtivo

Já foi dito que "a vitalidade da Universidade depende de sua abertura para as influências, demandas e necessidades da sociedade, as quais irão determinar a relevância do conhecimento produzido ou transmitido por ela, através da ação recíproca que se traduz em benefício para o ensino e a pesquisa, o que nos leva obrigatoriamente a uma releitura do conceito de extensão universitária” (1).

Muito mais do que simples prestação de serviços, unidirecionada, sem qualquer feed-back como ação retro-alimentadora dos seus objetivos, a extensão deve ser um conjunto integrado de atividades desenvolvidas. Um de seus requisitos imprescindíveis é sua focalização desde uma perspectiva multidisciplinar, incluindo, ao mesmo tempo, um enfoque político. Os problemas vivenciados por alunos e professores são problemas concernentes a várias ciências - tanto naturais quanto sociais - mas são também problemas da sociedade.

A integração Universidade-Sociedade-Estado propiciará a criação de condições de ensino-aprendizagem adequadas à nossa realidade, estimulando pesquisas básicas e aplicadas e promovendo a co-participação responsável no processo de desenvolvimento.

Na Escola Superior de Agricultura "Luiz de Queiroz" (ESALQ), essa perspectiva foi criada pela vontade de alunos e professores que, saindo das críticas estanques, implantaram uma extensão que atinge esses objetivos. Sua ação é reconhecida ao longo de sua história na área de extensão universitária, oferecendo grande número de cursos extracurriculares, de extensão etc. Atualmente, entretanto, há um importante diferencial em sua ação: mediante a atuação conjunta de alunos e professores, vem buscando executar a extensão como prática acadêmica que efetivamente interligue o saber acadêmico nas suas atividades de ensino e de pesquisa com as demandas da maioria da população.

Entre as inúmeras experiências desenvolvidas nessa área, destaca-se a relacionada com pequenos produtores de leite do município de São Pedro (SP).

\section{O caso de São Pedro (SP)}

A Legião Brasileira de Assistência (LBA), ligada à presidência da República, iniciou em 1988 um programa de crédito destinado a pequenos produtores agropecuários em todo país, com cerca de CZ\$ 800 disponibilizados àqueles interessados em realizar investimentos em suas propriedades. O empréstimo, em dinheiro, deveria ser pago sem juros ou correção monetária para uma instituição assistencial ou beneficente, em dez parcelas, após seis meses de carência.

Em São Pedro (SP), no alto da serra, um grupo de 38 agricultores na iminência de abandonarem suas propriedades e a agricultura por falta de recursos, 
conseguiram obter o crédito da LBA, ficando, no entanto, diante de um impasse: como devolver o dinheiro? (2)

Toninho - Tinha várias sugestões. Uma delas era devolver pra entidade assistencial em São Pedro, né? ... como se fosse "Lar dos Velhinhos", Santa Casa ... outra era montar um posto de gasolina ... outra idéia era montar uma agropecuária ...

Os agricultores, não-organizados e sem orientação, não chegavam a uma conclusão.

A primeira etapa do programa representava um desafio: fazer com que os agricultores percebessem que eles precisavam se organizar, formar uma associação representativa, participativa.

Luiz Veroneze - Muitos não tavam concordando formar a associação.

Antonio Veroneze - Não entrei porque a gente pensou que não era vantagem.

Nozor - Eles achavam que aquilo lá não ia dar certo, num tinha idéia nem o que era associação. (...) Eu sempre gostei de trabalbar junto com as pessoas, dividir o serviço com as pessoas, né? Há muitos anos atrás, como era lavoura de café, a região de café, então a gente não tinha um sistema de cooperativa, mai tinha aquele sistema de um sitiante ajudar o outro a trocar equipamento. É costume que a gente já tinha. Quando veio essa idéia de grupo, associação, a gente nem fazia idéia como era uma associação, como organizar ...

Como ocorre normalmente na agricultura familiar, esses produtores tinham o costume de trabalhar em mutirão, cooperativamente, nos momentos em que a mão-de-obra existente na família era insuficiente, ou de trocar trabalho de máquinas e equipamentos.

Entretanto, ao se reunirem para discutir a formalização de uma associação, os antigos conflitos existentes entre agricultores, entre famílias, afloravam e tornavam a tarefa difícil. Foi um longo processo de amadurecimento e de tomada de consciência do que realmente significava a sua união. Não era apenas agrupar, juntar as pessoas...

Ademir - Dentro desse trabalho, o que nós procurávamos é nunca tomar decisão por votação e sim tomar decisão por consenso de grupo. Então eva importante, $e$ a gente tinha grande preocupação em estar respeitando as pessoas do grupo e a gente e estar incluindo sempre as pessoas dentro do grupo, de maneira que elas sentissem como parte das decisões tomadas. (...) Esse estatuto (construído pelos agricultores) demorou aproximadamente três meses de reuniões, discutia-se o titulo, discutia-se cada pedacinho e após três meses eles já estavam amadurecendo com um processo de trabalho e construção coletiva (3).

A Associação dos Produtores Agropecuários do Município de São Pedro (APAMSP) nasceu em 1989, com 38 associados. Porém, criar a associação era 
uma coisa... fazê-la consolidar-se, amadurecer os vínculos entre os seus associados, era outra. Como fazê-lo?

\section{O GESP e a rotina da extensão}

A LBA, preocupada com a execução do projeto, convidou o Departamento de Economia, Administração e Sociologia Rural da ESALQ-USP para realizar o acompanhamento técnico e organizacional dos agricultores. O Projeto Assessoria Técnica, Organizacional e Financeira à associação de pequenos produtores e suas microunidades produtivas (MUPs) foi implementado mediante convênio firmado com a Fundação Legião Brasileira de Assistência (FLBA) e Fundação Estudos Agrários Luiz de Queiroz (FEALQ).

No final de 1989 foi instituído o Grupo de Extensão de São Pedro (GESP), composto por alunos, dois professores, um técnico especializado em extensão e um assistente social. Entre seus objetivos destacavam-se:

- contribuir para que os produtores e suas famílias conseguissem se desenvolver técnica, econômica e socialmente, tornando-se cada vez mais capazes de assumir seus papéis na sociedade;

- propiciar condições para que alunos e professores fossem capacitados na ação e desenvolvessem trabalhos junto à organização de produtores familiares;

- realizar pesquisas de acompanhamento e avaliação junto aos produtores e sua organização;

- assessorar os produtores na condução de suas atividades visando otimizar o rendimento dentro de suas realidades;

- promover uma interação maior entre o conhecimento dos produtores e aquele gerado na Universidade e nos Centros de Pesquisa.

Desde então, repete-se a rotina: duas vezes por semana, todos os meses, o ano inteiro, alunos estagiários partem da ESALQ e sobem a serra de São Pedro, onde percorrem as propriedades, trocam idéias com os agricultores, aprendem. A intervalos regulares, novos alunos incorporam-se ao grupo, passando por um processo de transição no qual são guiados pelos colegas mais experientes.

Utilizando metodologia participativa, os estagiários assessoram os produtores em suas atividades de organização e produção de leite, grãos e olerícolas e, acima de tudo, na construção de uma sociedade mais justa. Sempre que necessário, contatam outros departamentos da ESALQ, envolvem professores nas demandas identificadas, promovem palestras, cursos etc.

O GESP incorpora o que preconiza aos agricultores: os alunos planejam participativamente; decidem por consenso; respeitam conhecimentos, experiências e valores pessoais; criam condições de liberdade de opções e idéias; sociali- 
zam as informações produzidas; consideram que a motivação está nas pessoas, não nas atividades; valorizam a interação entre os participantes do grupo.

Além de visitar semanalmente os produtores e a Associação, quando "batem muito papo, bebem, comem e prestam informações técnicas aos produtores", os estagiários realizam excursões, palestras, dias de campo, cursos, experimentos, intercâmbio estudantil, entre outras atividades, e publicam um jornal mensal da APAMSP, desde 1993.

Como atividade interna, reúnem-se no Departamento de Economia, Administração e Sociologia semanalmente, para planejar novas ações, distribuir tarefas, trocar informações, avaliar o projeto e promover a capacitação dos membros dos grupos.

\section{O difícil caminhar}

No final dos anos 80 a única saída para os agricultores, quase falidos, era a estrada que descia a serra e levava para a vida urbana, onde deveria estar o tal "progresso" e a qualidade de vida que não existia no campo. Proprietários de pequenas áreas - entre três e dez alqueires -, eles viviam exclusivamente da produção de leite, mas, com baixa tecnologia, a produção era insuficiente para garantir a sua subsistência e a de de suas famílias.

A união APAMSP e GESP conseguiu mudar radicalmente o destino desses agricultores. Por intermédio da extensão, a organização e a tecnologia chegaram ao alto da serra. Mas a tecnologia assustava!

Soares - No dia em que o técnico da ESALQ falou da necessidade de colocar mil quilos de adubo em cada alqueire de terra, quase caímos duros. Só que valeu a pena.

E como valeu! Soares, que antes do projeto associativo enchia 60 carretas de 1300 quilos cada, no primeiro ano mudou para 80, no segundo para $100 \mathrm{e} \mathrm{em}$ 1993 já enchia 120 carretas.

As propriedades foram remanejadas, buscando o seu melhor aproveitamento. Pastagens divididas em piquetes, onde o gado pastava em rotação; área reservada para o plantio de capim napier e milho em rotação com aveia, que garantiam alimentação no cocho durante o dia e se transformam em silagem para consumo no inverno. A inseminação artificial melhorou a qualidade do gado e a orientação dada pela ESALQ-USP resultou no uso correto de vacinas e medicamentos. Nas épocas de colheita e formação dos silos, os agricultores reúniam-se em mutirões, abriam valetas, colhiam, transportavam, armazenavam em valas, cobrem com lonas e deixam estocados até o inverno.

A produção de leite também espanta - positivamente - os agricultores: até 1988, antes da organização do grupo, Soares tinha 12 vacas que produziam jun- 
tas 50 litros de leite por dia. Seis anos depois, com 15 vacas, produz 200 litros ao dia e atualmente 300 litros. E Soares sabe:

- Vaca bem alimentada produz mais e melhor.

Em 1994, a LBA voltou a destinar recursos ao grupo, o qual decidiu montar um laticínio. Como os recursos eram suficientes apenas para a aquisição de parte dos equipamentos necessários, o restante e a contrução do prédio foram assumidos por 17 componentes do grupo e, posteriormente, por dois grandes produtores da região. Este grupo constitui o de sócio-proprietários.

Em 1997 - nove anos depois da formação da APAMSP - o laticínio foi inaugurado, alcançando, em seis meses, a capacidade instalada de 5 mil litros diários. Um ano depois, com investimentos de fundos gerados pela própria usina, esta foi ampliada para a capacidade de 15 mil litros/dia. Segundo dados de novembro de 2000, o laticínio capta leite de 53 produtores.

Ademir - Antes da construção do laticinio, os produtores vendiam o leite para as indústrias que pagavam o preço que elas queriam, já que eles não tinham nenhum controle sobre o processo de venda deste leite.

Toninho-E outra coisa que favoreceu bastante a gente é a parte do carreto, porque quando a gente entregava nos outro laticinio, eles desconta dez, doze por cento e aqui nóis pagamos três, dois por cento.

Ademir - Durante esses três últimos anos de funcionamento do laticinio, nós conseguimos pagar para os produtores 3 centavos acima do preço que eles recebiam se entregassem para qualquer outro fornecedor de mercado.

Toninho - Uma outra coisa que o laticinio fez o ano passado é que pagou um preço base o ano inteiro, coisa que os outros laticinios pagam bastante no inverno $e$ no verão cai o preço.

Hoje o Leite do Campo, de excelente qualidade, ganha consumidores tanto em São Pedro quanto em municípios da região.

Ademir - Atualmente o laticinio recebe cerca de 13 mil litros de leite por dia, sendo 6000 litros de leite tipo B e 7 mil litros de leite tipo C, que é distribuido na região de Piracicaba, Santa Bárbara, Limeira, Águas de São Pedro e São Pedro.

Toninho - A Associação tá pensando em montar um postinho de óleo diesel prá fornecer pros associados e a gente tá entrando, comprando cesta básica, tem mai coisa ai: o laticinio tá pensando em fazer iogurte, em fazer queijo e leite B. Leite $B$ já deve tá entrando agora no mês de julho. Então ai eu acho que tem tendência em melhorar.

\section{E os problemas da comunidade?}

A Associação, além de promover maior rentabilidade aos agricultores associados, desenvolveu também outras de interesse da comunidade. 
Carlão - [Então, aquela] escola ali também, a gente conseguiu junto, nós se organizamos, pedimos pra prefeita, que na época era a Antonieta, e a gente pediu, a gente viu quanto aluno tinha pra aqui - a gente tinha 137 alunos. Dai a gente pediu pra prefeita começar esta escola onde ela construiu. É uma escola boa, mil metros quadrados, hoje está com 270 alunos...

Ademir - Outra conquista foi a construção do posto de saúde no Bairro Santo Antonio que era uma necessidade da população, requerida bá muito tempo e través desta organização da Associação junto com a comunidade é que se conseguiu a criação deste posto de saúde que funciona todos os dias pelo menos durante um periodo.

Toninho - A Associação hoje até tem pranos de saúde ...

\section{Agricultores na ESALQ}

Uma vez por ano, os agricultores da APAMSP e os componentes do GESP participam de uma aula na ESALQ, na disciplina de Sociologia e Extensão Rural, quando relatam a história da APAMSP e discutem com os alunos o processo pelo qual passaram. São francos e, em alguns momentos, duros: fazem os alunos refletirem sobre o que significa a oportunidade - "sorte" - de estarem sentados em bancos da Universidade enquanto eles - agricultores - não tiveram a oportunidade de terminar o primeiro grau. De forma objetiva, levam os alunos a pensar/ repensar o papel e a responsabilidade que eles têm perante a sociedade que lhes dá essa oportunidade e, em especial, com pequenos agricultores, como eles.

Este é mais um produto da atividade da extensão, que permite aos alunos que não participam do projeto conhecer o trabalho e, se interessados, participar dele.

\section{À guisa de conclusão}

Não se deve imaginar que tudo deu certo e que todos viveram felizes para sempre. O projeto de extensão em São Pedro, com mais de 10 anos, continua e é um processo dinâmico: a cada problema resolvido, outros aparecem.

Não pretendemos, neste texto, justificar "à luz da teoria” os resultados alcançados, mas deixamos aos associados da APAMSP a tarefa de concluí-lo:

Carlão - Não temos dinheiro hoje. Falar que tem bastante, não tem. Porque a associação não é lugar de fazer um montão de dinheiro e sim ajudar o pequeno produtor e entender que a turma tem que tá junto.

Margarida - Se nós não desistimos até agora é porque a gente acredita e tem que continuar acreditando. E procura a gente se educar cada vez mais pra conviver melhor com os outro.

Carlão - ... era mais um talvez vivendo na favela, indo prá lá, indo embora.

Margarida - O que diria é isso: vale a pena a gente lutar. Se houver chance pra melhorar a associação, fazer crescer o laticinio, a própria associação continuar 
esse trabalho. Eu acho que vale a pena porque realmente nós não nascemos pra viver sozinho. Não, é em grupo que a gente se torna mais forte, né?

Carlão - Valeria a pena começar tudo de novo hoje. Tudo que a gente começou lá em 89, fosse pra começar hoje, poderia começar de novo. Vale a pena..

\section{Notas}

1 Folder do Grupo de Trabalho de Extensão de Serviços à Comunidade - USP.

2 Os depoimentos dos agricultores apresentados neste texto fazem parte de entrevistas realizadas por alunos da disciplina de Comunicação Rural, da ESALQ para a elaboração de um vídeo pelo Laboratório de Vídeo do LAN-ESALQ, coordenado por professora Laura A. Martirani, T.E.S. Ademir de Lucas, com a participação do aluno bolsista Gilberto Ramos Rodrigues.

3 T.E.S. Ademir de Lucas é coordenador executivo do Projeto, Departamento de Economia, Administração e Sociologia, ESALQ-USP.

Referências bibliográficas

COSTA, B. O negócio do pequeno é se juntar. Revista DBO RURAL, p. 58-62, fev. 2000.

LUCAS, A. Viabilizando a produção familiar do leite. CEPEA-FEALQ-USP, Boletim do Leite, ano 6, n. 64, jul. 1999.

PEREIRA, M.T. \& LUCAS A. Assessoria Técnica, Organizacional e Financeira a Associação de Pequenos Produtores e suas Microunidades Produtivas (MUPs). Legião Brasileira de Assistência, USP-ESALQ,-FEALQ. Relatório de Pesquisa, ago. 1994.

RAMOS, M.A. De barriga cheia. São Paulo, Globo Rural, p. 47-50, jul. 1994.

Marly Teresinha Pereira é professora do Departamento de Economia, Administração e Sociologia da ESALQ-USP, mestre em Economia Agrária e doutoranda em Sociologia pela Universidad ARCIS-Chile. 